\title{
REFLEXO DAS VARIAÇÕES MORFODINÂMICAS PRAIAIS NAS CARACTERÍSTICAS TEXTURAIS DOS SEDIMENTOS DA PRAIA DA ARMAÇÃO, SALVADOR, BAHIA
}

\author{
ABÍLIO CARLOS DA SILVA PINTO BITTENCOURT*, \\ FÉLIX FERREIRA DE FARIAS** e ADEMAR ZANINI JÚNIOR***
}

\begin{abstract}
Monitoring of two beach profiles at the extreme ends of the Armação Beach in Salvador, Bahia, during the period of March/1982 to September/1984, has revealed that their most significant morphodynamic changes are also reflected in sediment textural features such as the median, the $1 \%$ percentile $(\mathrm{C})$, and sorting. Both profiles exhibit a cyclic evolutionary trend characterized by three well defined, closely synchronous, stages (I, II, and III). In stages I and III, related to the arrival of cold-fronts to the area, distinctly high values for the median and for $\mathrm{C}$ as well as low values for the sorting are reached in the two profiles. In addition, inasmuch as the highest values of the median and $\mathrm{C}$ along with the lowest of sorting were recorded in the profile of the beach section subjected to more wave turbulence, these textural parameters served also to discriminate the two studied beach portions on the basis of their energy levels. No correlation has been found between skewness and the main morphologic variations. This is believed to result from the obliteration of the major, seasonal changes by the daily, small ones.
\end{abstract}

INTRODUÇÃO O monitoramento das variações morfo'dinâmicas de uma praia, pela coleta e análise, em série, de dados ao longo do tempo, é, seguramente, um método eficiente e relativamente de baixo custo de se obter modelos conceituais de relações geodinâmicas. Os trabalhos realizados sobre esse assunto (Shepard \& La Fond 1940, Shepard 1950, Ziegler et al. 1959, Inman \& Filloux 1959, Ziegler \& Tuttle 1961, Kowsman 1970, Davis 1978, Dingler 1981, Farias et al. 1985, entre outros) ativeram-se, em sua quase totalidade, à análise de mudanças volumétricas (erosão ou construção) expressas pela variabilidade do perfil de praia, com uma ênfase particular nas variações sazonais. Exceção é feita, pelo conhecimento dos autores, ao trabalho de Nordstrom (1977), que procurou comparar, do ponto de vista textural, as variações temporais nos sedimentos de quatro praias do litoral de New Jersey (EUA) por um período de oito meses consecutivos, com os ciclos erosivos e construtivos por ele aí determinados, sem contudo identificar correlações evidentes. Nordstrom ( $o p$. cit.) concluiu que, pelo fato de os parâmetros estatísticos serem muito sensíveis, os grandes ciclos de erosão e construção são obscurecidos pelas variações diárias, no perfil praial, não podendo assim ser refletidos nos valores daqueles. $O$ presente trabalho adota uma abordagem semelhante à de Nordstrom (1977), só que, no caso, para se estudar uma praia localizada numa região tropical na costa atlântica da cidade de Salvador (Fig. 1). Esta praia, denominada Praia de Armação, foi estudada por Farias et al. (1985), que nela identificaram uma sucessão de ciclos erosivos e construtivos relacionados às variações sazonais no regime de ventos local. Esses autores monitoraram as variações do perfil da Praia de Armação mediante 45 observações realizadas durante 19 meses consecutivos (de março de 1982 a setembro de 1983). No atual trabalho, essas medidas foram expandidas até setembro de 1984, perfazendo mais 18 observações, seguindo a metodologia descrita por Farias et al. (op. cit.). Desse modo, dentro do quadro acima exposto, o objetivo que se quis alcançar foi investigar, durante o período de março de 1982 a setembro de 1984 , as variações temporais e espaciais na textura dos sedimentos da Praia de Armação. Para tanto, foram utilizadas areias amostradas sempre na linha de máximo espraiamento relacionada à preamar anterior. Estas amostras, representativas de dois perfis que ocupam as extremidades da praia, aqui denominados perfis 1 e 2 (Fig. 1), foram coletadas nas primeiras lâminas de areia da superfície, com até $2 \mathrm{~cm}$ de profundidade. De cada amostra, secada e quarteada," foi retirada uma quantidade, em torno de $50 \mathrm{~g}$, da qual se eliminaram os sais solúveis. Após esse tratamento, a amostra foi peneirada a seco com Rotap, através de um conjunto de peneiras com intervalos de $1 / 2 \Phi$.

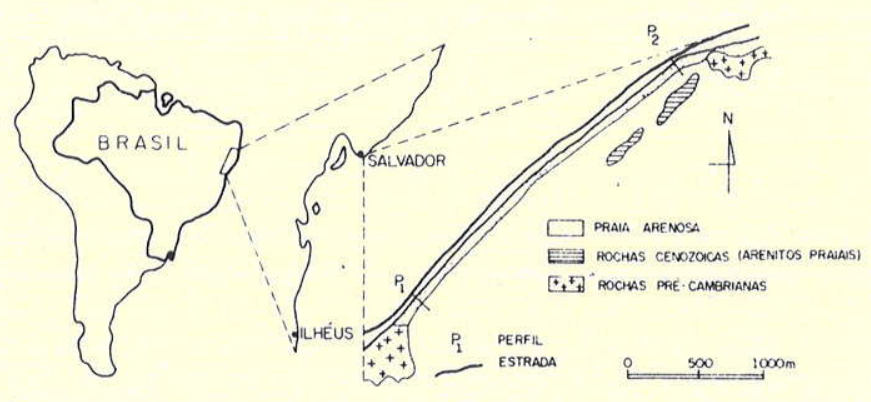

Figura 1 - Mapa de localização da Praia de Armação mostrando o posicionamento dos perfis (segundo Farias et al. 1985)

CARACTERISTICAS FISIOGRAFICAS E CLIMATICAS DA AREA ESTUDADA As características fisiográficas e climáticas da costa atlântica de Salvador já foram descritas por Farias et al. (1985, p. 49), como segue: "A praia de

* Programa de Pesquisa e Pós-Graduação em Geofísica e Instituto de Geociências, UFBa. Campus Universitário da Federação, Rua Caetano Moura, 123, CEP 40000, Salvador, BA, Brasil

** Instituto de Geociências, UFBa. Campus Universitário da Federação, Rua Caetano Moura, 123, CEP 40000, Salvador, BA, Brasil

*** Curso de Graduação em Geologia, UFBa. Campus Universitário da Federação, Rua Caetano Moura, 123, Salvador, BA, Brasil 
Armação, com cerca de $3 \mathrm{~km}$ de extensão e uma orientação aproximada NE-SE, tem a forma de uma suave enseada, com os seus extremos limitados por promontórios rochosos do embasamento cristalino que bloqueiam qualquer trânsito litorâneo de materiais entre a mesma e as praias vizinhas" (Fig. 1). "O clima da área é do tipo tropical úmido com alta pluviosidade, havendo uma predominância dos ventos alíseos (NE-E-SE) que, de uma maneira geral, sopram regularmente durante todo o ano (Santos 1962). Segundo Peixoto (1968), as médias anuais indicam $70,1 \%$ dos ventos provindos do setor NE-E-SE, sendo $35,1 \%$ de E e $14,6 \%$ de NE. Os ventos de $S$, que são pouco freqüentes, são entretanto os mais violentos, normalmente atingindo velocidades médias de $5 \mathrm{~m} / \mathrm{seg}$ (Diretoria de Hidrografia e Navegação-DHN 1976). De uma maneira geral os ventos do quadrante SE apresentam velocidades médias anuais de $4 \mathrm{~m} / \mathrm{seg}$, a não ser quando provêm de SSE, acompanhados de ventos $S$, quando passam a ter velocidades médias de $5 \mathrm{~m} / \mathrm{seg}$ (DHN $o p$. cit.). Os ventos de $\mathrm{E}$ e de NE são os mais fracos, com velocidades médias anuais de $3 \mathrm{~m} / \mathrm{seg}$ (DHN op. cit.). No outono e inverno, a costa de Salvador passa a sofrer a influência freqüente da Frente Polar Atlântica em seu avanço para latitudes mais baixas, quando se intensificam as chuvas, geralmente acompanhadas de veritos provindos de S e SSE (Seplantec-Secretaria de Planejamento, Ciência e Tecnologia do Estado da Bahia 1978). Os meses de maiores pluviosidades são abril e maio, com valores médios, respectivamente, de 272,8 e $297,9 \mathrm{~mm}$ (Peixoto op. cit.)."

\section{CICLOS EROSIVOS E CONSTRUTIVOS Os gráficos}

da figura 2 mostram as modificações topográficas sofridas pelos perfis 1 e 2 ao longo do período de observação. Em relação à faixa de tempo que vai de março de 1982 a setembro de 1983 são a seguir explicitadas as principais características apontadas por Farias et al. (1985):

a. Houve no perfil 1 três fases erosivas $(1,3$ e 5$)$ e duas construtivas ( 2 e 4 ), e, no perfil 2 , uma fase erosiva (3), duas construtivas ( 1 e 4 ) e uma em que praticamente não houve movimentação de material (2);

b. É notável o comportamento inverso do perfil 1 em relação ao 2. Assim, embora com algumas defasagens de poucos dias entre os seus limites - e à exceção das fases 2 e 3 do perfil 1 e a correspondente fase 2 do perfil 2 -, para cada fase do perfil 1, seja erosiva ou construtiva, corresponde uma fase inversa no perfil 2 , esse fato sugerindo a existência de um transporte efetivo de sedimentos paralelamente à praia, com os sentidos se invertendo ciclicamente ao longo do tempo;

c. Há trocas significativas de materiais no sentido da face da praia para a antepraia e vice-versa, movimentos esses, juntamente com os que são feitos longitudinalmente à praia, que estão estreitamente relacionados com o regime de ventos atuante na Praia de Armaçã̀o;

d. As fases erosivas em que houve uma pronunciada erosão no perfil 1 (fases 1 e 5 , Fig. 2) e, conseqüentemente, uma construção no perfil 2 (fases 1 e 4 ) coincidiram com a chegada de frentes frias na costa de Salvador, acompanhadas por ventos provindos de S e SSE. Esses ventos, então, induziram a formação de uma deriva litorânea do perfil 1 para o 2 (Fig. 1), além de, pelo fato de serem fortes, terem gerado grandes ondas que, ao se arrebentarem diretamente na face da praia, retiraram material da mesma para a antepraia; e. O processo de troca de materiais entre a face da praia e a antepraia só não deve ocorrer nas proximidades do perfil 2 devido à presença de afloramentos rochosos na antepraia superior defronte ao mesmo (Fig. 1), que impede esse trânsito;

f. A pequena fase erosiva do perfil 1 (fase 3) (Fig. 2) é devida à existência de ventos de $\mathrm{SE}$, ainda relativamente fortes, dissociados de ventos de S. Desse modo, enquanto o perfil 1 está erodindo, o 2, protegido pelos afloramentos rochosos, permanece praticamente inalterado (Fig. 2), o que permite supor que os ventos do quadrante SE devem ter sido eminentemente de SE, quando então não provocariam nenhuma deriva na praia (Fig. 1). Nesse caso, todo o material erodido no perfil 1 nessa fase deve ter sido transferido para a antepraia;

g. A grande fase construtiva do perfil 1, fase 4 (Fig. 2), que corresponde à fase erosiva 3 do perfil 2, está relacionada a uma predominância dos fracos ventos de $\mathrm{E}$ e NE, que induzem a formação de uma deriva litorânea do perfil 2 para o 1 (Fig. 1). Ademais, nessa fase deve ter havido também um transporte de material da antepraia para a face da praia, ao longo de toda a extensão da Praia de Armação, exceção feita ao trecho próximo do perfil 2, pelos motivos discutidos anteriormente e que estão relacionados à presença de afloramentos rochosos na antepraia defronte a esse perfil.

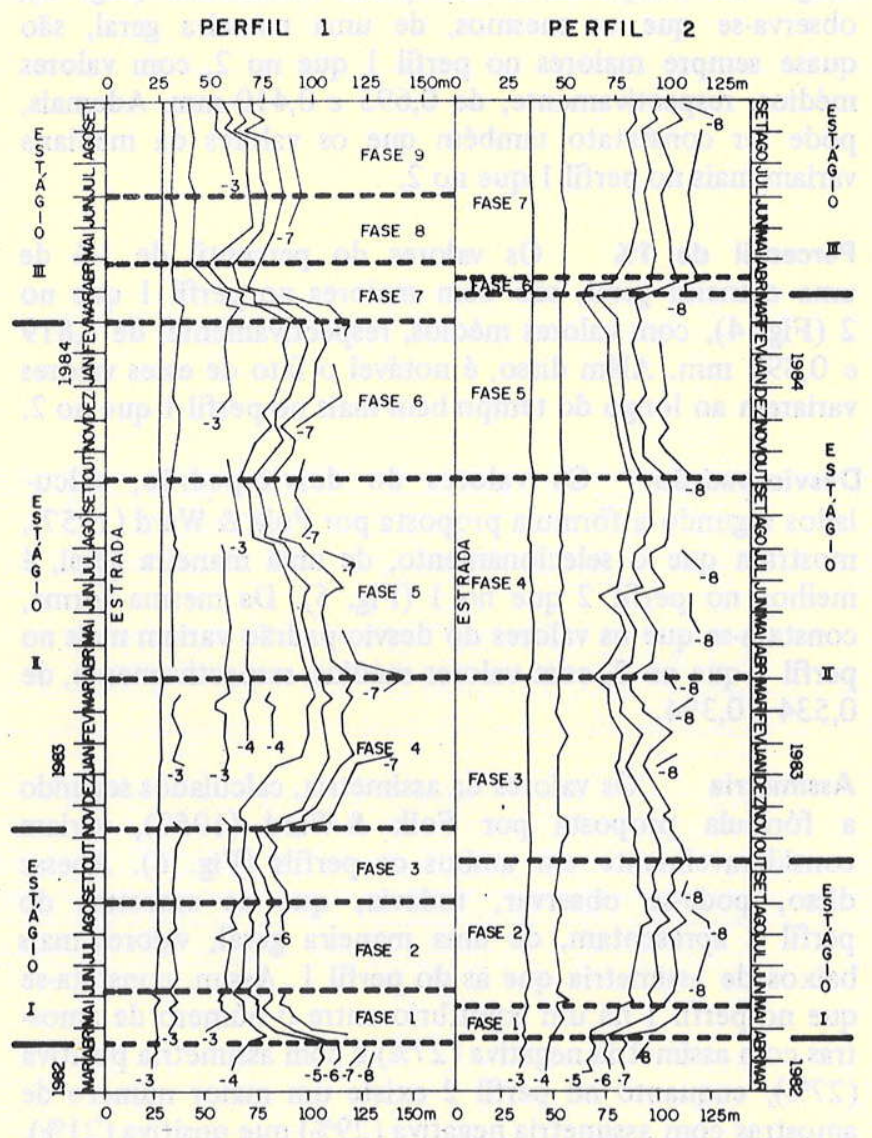

Figura 2 - Diagramas de linhas de contorno para os perfis 1 e 2. Os contornos ligam pontos de cotas iguais na superficie da praia, em metros, medidas ao longo do tempo em relação a um datum que passa pela estrada marginal à Praia de Armação (Fig. 1) (modificado de Farias et al. 1985) 
No período de outubro de 1983 a setembro de 1984 que, conforme já se mencionou, corresponde à faixa de tempo monitorada durante o presente trabalho, foi observada uma recorrência com características bem assemelhadas de fases já observadas anteriormente nos perfis 1 e 2. Assim, observa-se que as fases $6,7,8$ e 9 , no perfil 1 , correspondem, respectivamente, às fases $4,1,2$ e 3 do mesmo perfil (Fig. 2). Ademais, os autores puderam verificar que as mesmas estão relacionadas com os mesmos tipos de ventos apontados por Farias et al. (1985) para as fases 4, 1, 2 e 3. Da mesma maneira, as fases 5,6 e 7 , no perfil 2 , correspondem, respectivamente, às fases 3,1 e 2 do mesmo perfil (Fig. 2), também as primeiras relacionadas aos mesmos tipos de ventos já apontados por Farias et al. (op. cit.) para as segundas. É também notável, embora com pequenas defasagens no tempo, a coincidência entre seus limites e as características inversas das fases 6 e 7 , no perfil 1 , e as correspondentes fases 5 e 6 , no perfil 2 (Fig. 2).

ANALISE COMPARATIVA ENTRE OS PERFIS 1 E 2 A seguir será feita, do ponto de vista textural, uma análise comparativa entre os perfis 1 e 2 . Serão analisados os comportamentos da mediana, do percentil de $1 \%$ (C), do desvio-padrão, da assimetria e do diagrama CM.

Mediana Comparando-se os valores da mediana ao longo do tempo' entre os perfis analisados (Fig. 3), observa-se que os mesmos, de uma maneira geral, são quase sempre maiores no perfil 1 que no 2 , com valores médios, respectivamente, de 0,695 e $0,410 \mathrm{~mm}$. Ademais, pode ser constatato também que os valores da mediana variam mais no perfil 1 que no 2 .

Percentil de $1 \%$ Os valores do percentil de $1 \%$ de uma maneira geral, são bem maiores no perfil 1 que no 2 (Fig. 4), com valores médios, respectivamente, de 1,819 e $0,890 \mathrm{~mm}$. Além disso, é notável o fato de esses valores variarem ao longo do tempo bem mais no perfil 1 que no 2 .

Desvio-padrão Os valores do desvio-padrão, calculados segundo a fórmula proposta por Folk \& Ward (1957), mostram que o selecionamento, de uma maneira geral, é melhor no perfil 2 que no 1 (Fig. 5). Da mesma forma, constata-se que os valores do desvio-padrão variam mais no perfil 1 que no 2 , com valores médios, respectivamente, de 0,534 e 0,394 .

Assimetria Os valores da assimetria, calculados segundo a fórmula proposta por Folk \& Ward (1957), variam consideravelmente em ambos os perfils (Fig. 6). Apesar disso, pode-se observar, todavia, que as amostras do perfil 2 apresentam, de uma maneira geral, valores mais baixos de assimetria que as do perfil 1. Assim, constata-se que no perfil 1 há um equilíbrio entre o número de amostras com assimetria negativa (27\%) e com assimetria positiva (27\%), enquanto no perfil 2 existe um maior número de amostras com assimetria negativa (29\%) que positiva (21\%).

DIAGRAMA CM Os diagramas CM (Passega 1957) construídos a partir de amostras coletadas nos perfis 1 e 2 (Fig. 7) apresentam, no perfil 2, um padrão de distribuição com pontos mais concentrados na parte granulometricamente mais fina ( $<1.000$ mícrons), o que não se observa no perfil 1. Nas frações granulometricamente mais grossas
( $>1.000$ mícrons), ambos aos perfis mostram um padrão de distribuição com pontos dispersos, mais notável no perfil 1 que no 2 . Em ambos os gráficos os pontos se dispõem aproximadamente paralelos à linha $\mathrm{C}=\mathrm{M}$.

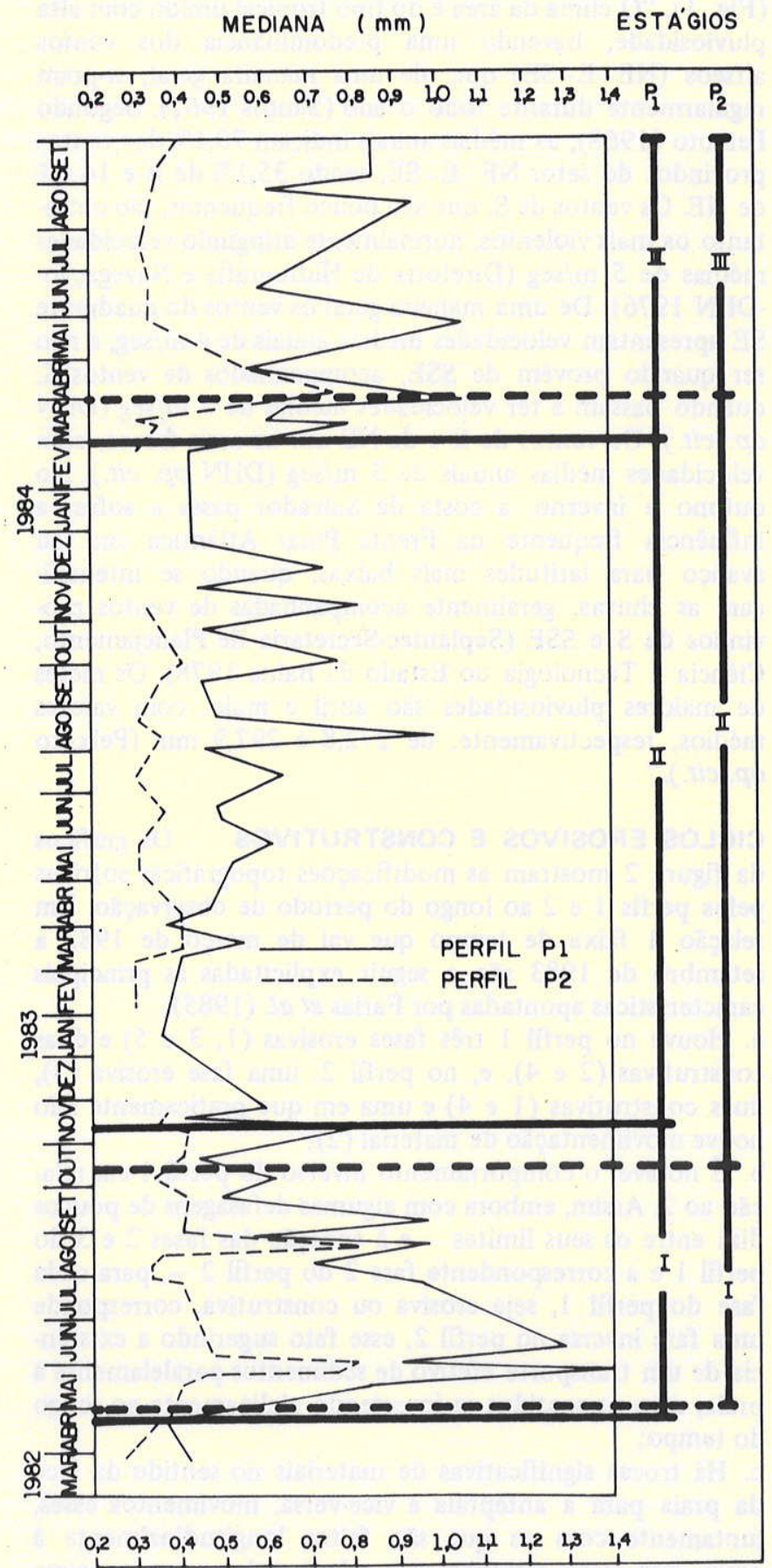

Figura 3 - Variações dos valores da mediana, ao longo do tempo, nos perfis 1 e 2

\section{RELAÇÃO ENTRE OS ATRIBUTOS TEXTURAIS E OS CICLOS EROSIVOS E CONSTRUTIVOS Do ponto de} vista textural, tanto no perfil 1 quanto no 2 , os gráficos de variações dos valores da mediana (Fig. 3 ), do percentil de $1 \%$ (Fig. 4) e do desvio-padrão (Fig. 5) apresentam três estágios, aqui denominados I, II e III, cujos limites entre si, 
em ambos os perfis, embora não apresentando linhas bem marcadas, podem, todavia, ser delimitados dentro de estreitas faixas de tempo. Assim, dentro dessas faixas, os limites entre os estágios foram posicionados em linhas de tempo que coincidem, de uma maneira geral, com importantes modificações sofridas pelos perfis da praia (Fig. 2) e que, como se verá adiante, estão estreitamente relacionadas à dinâmica dos referidos estágios. Exceção feita ao gráfico das variações dos valores da assimetria (Fig. 6) e ao diagrama CM (Fig. 7), nos quais os estágios I, II e III não puderam ser identificados. Os limites entre esses estágios marcam, aproximadamente, em ambos os perfis, à exceção do limite entre os estágios I e II no perfil 2, mudanças abruptas e de grande amplitude nos perfis das praias (Fig. 2). O início dos estágios I e III é marcado por uma grande e rápida erosão do perfil 1 , com uma conseqüente grande e rápida construção no perfil 2 (Fig. 2). Já o início do estágio II é caracterizado por uma brusca e grande construção no perfil 1 e por uma lenta e gradual erosão no perfil 2.

Pode-se observar que, tanto no perfil 1 quanto no 2, os estágios I e III, de uma maneira geral, apresentam valores da mediana (Fig. 3) e do percentil de $1 \%$ (Fig. 4) maiores que no estágio II. Da mesma sorte, constata-se pelo exame da figura 5 que nos estágios I e III, em ambos os perfis, as amostras são em sua maioria moderadamente selecionadas, enquanto no estágio II são, de uma maneira geral, bem selecionadas.

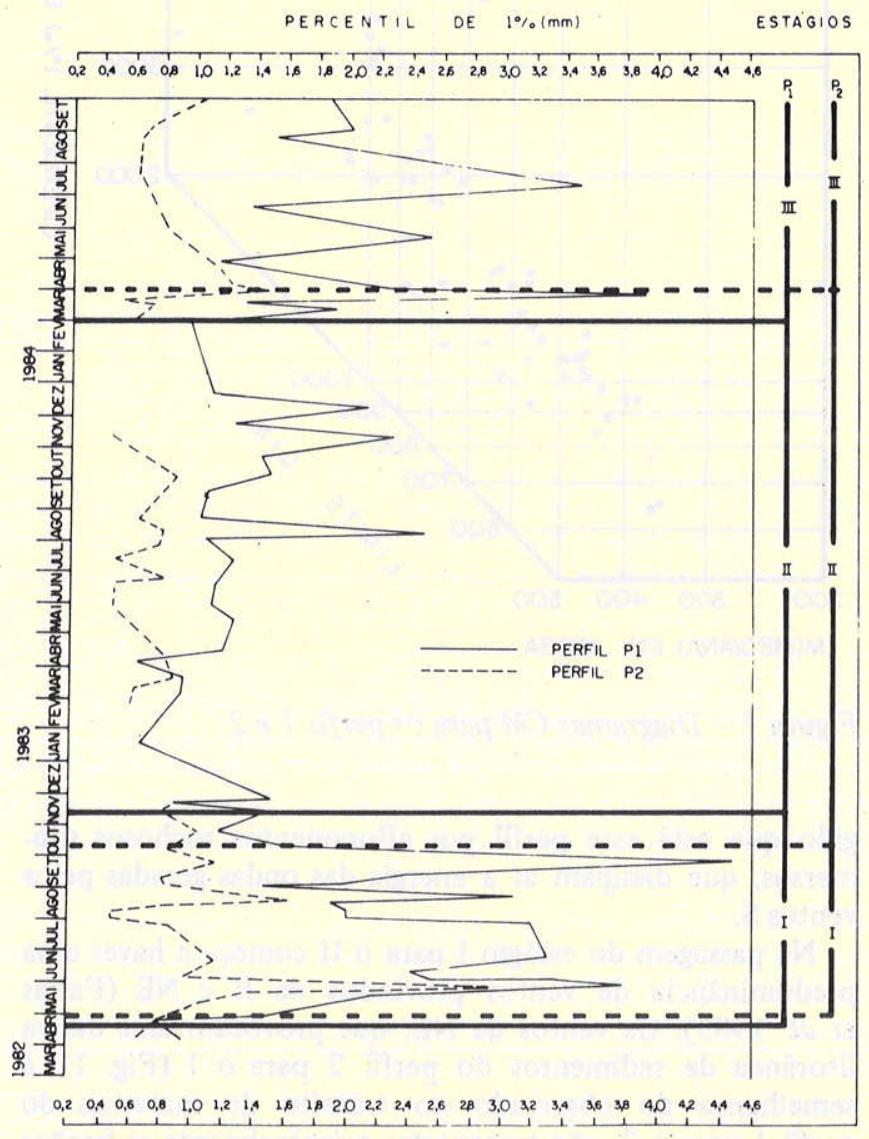

Figura 4 - Variações dos valores do percentil de 1\% (C), ao longo do tempo, nos perfis 1 e 2

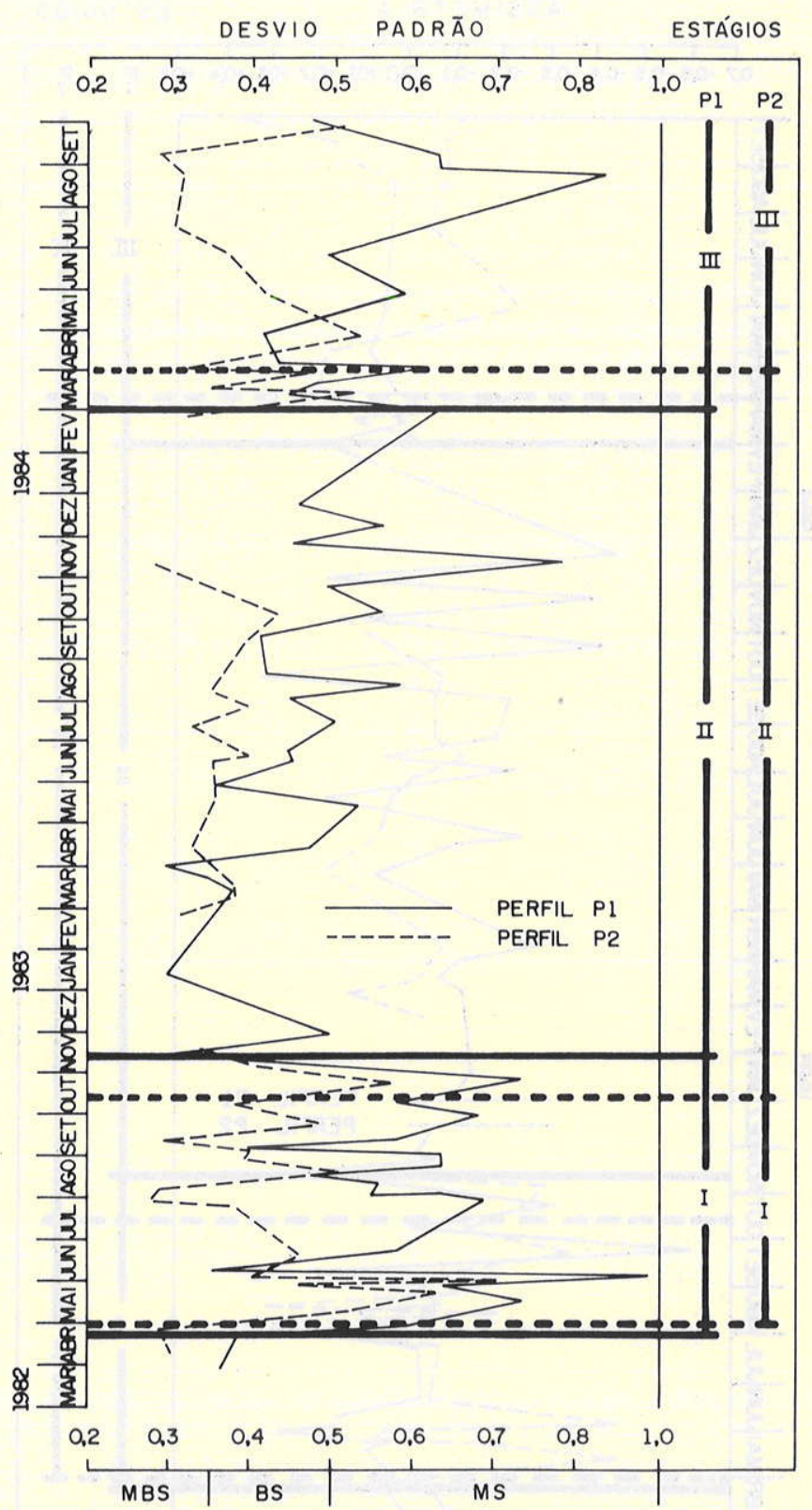

Figura 5 - Variações dos valores do desvio-padrão, ao longo do tempo, nos perfis 1 e 2: MBS, muito bem selecionado; BS, bem selecionado; MS, moderadamente selecionado

DISCUSSÃO E CONCLUSÕES Diferentemente dos resultados obtidos por Nordstrom (1977) em praias do litoral de New Jersey (EUA), a maioria dos atributos texturais aqui abordados, apesar das pequenas variações que diariamente podem ocorrer nos perfis praiais (Schwartz 1968), consegue refletir, ao longo do tempo, as mudanças mais abruptas ocorridas nos perfis 1 e 2 . Assim, o fato de tanto o perfil 1 quanto o 2 apresentarem maiores valores da mediana e do percentil de $1 \%$ nos estágios I e III (Figs. 3 e 4) está relacionado à chegada de frentes frias na costa atlântica de Salvador. Desse modo, durante a época do ano que predominam os ventos provindos de $\mathrm{S}$, que acompanham as frentes frias (Farias et al. 1985), são geradas ondas relativamente grandes que retiram da face da praia do perfil 1 as frações granulométricas mais leves, carreando-as 
ASSIMETRIA

ESTÁGIOS

$0,7-0,6 \cdot 0,6 \cdot 0,4 \cdot 0,3 \cdot 0,2-0,1 \quad 0,0+0,1+0,2+0,3+0,4+0,5 \quad P_{1} \quad P_{2}$

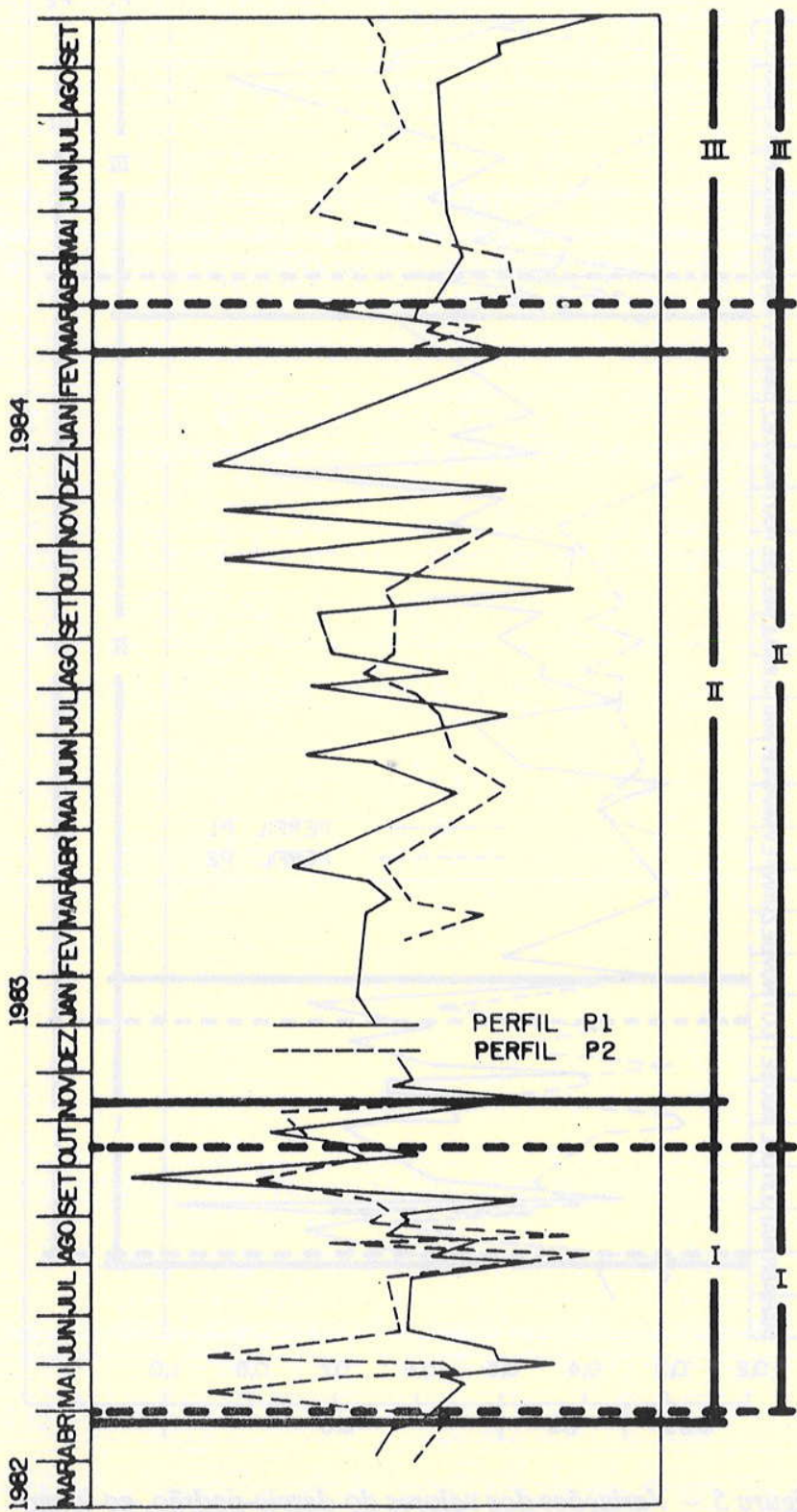

$-0,7-0,6-0,5-0,4-0,3-0,2-0,1 \quad 0,0+0,1+0,2+0,3+0,4+0,5$

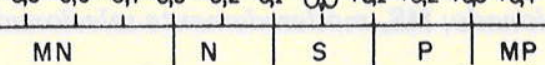

Figura 6 - Variações dos valores da assimetria, ao longo do tempo, nos perfis 1 e 2: $\mathrm{MN}$, muito negativo; $\mathbf{N}$, negativo; $\mathrm{S}$, simétrico; $\mathbf{P}$, positivo; MP, muito positivo

para a antepraia, conforme se discutiu. Ao mesmo tempo, parte das frações grossas que se vão concentrando na face da praia vai migrar para o perfil 2 por força da deriva litorânea que os ventos $S$ induzem do perfil 1 para 02 (Fig. 1), fato este que está em acordo com o observado por Evans (1939) e Komar (1977), de que na face da praia as partículas mais grossas se deslocam longitudinalmente com uma velocidade maior que as mais finas. Assim, a granulometria também aumenta concomitantemente no perfil 2 , embora não tanto quanto no 1 , já que, como já se mencionou, praticamente nenhum material fino é retirado da face da praia para a antepraia na altura do perfil 2 , prote-

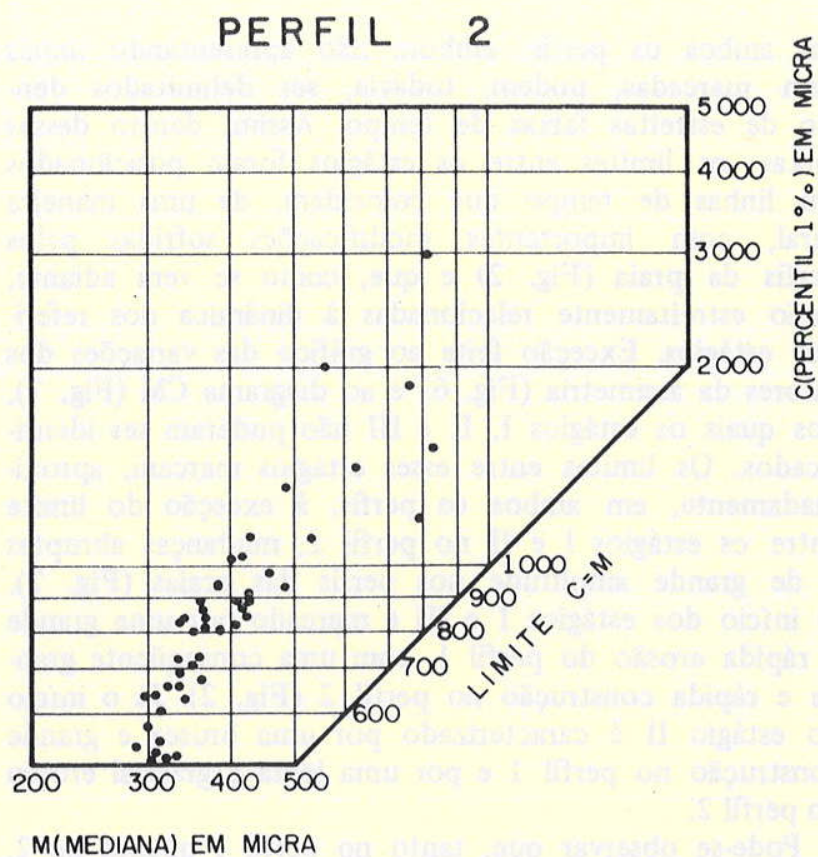

PERFIL $\quad 1$

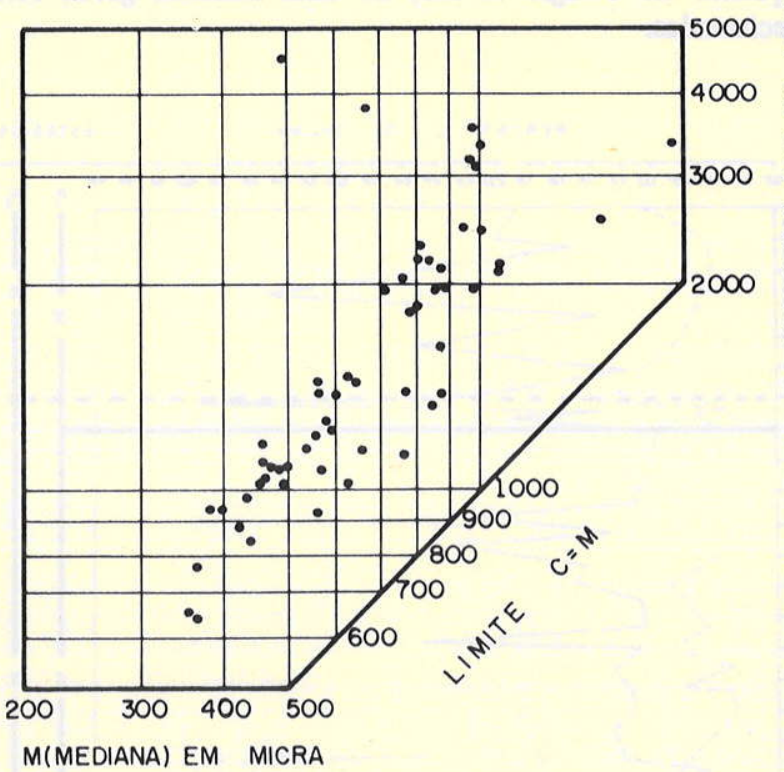

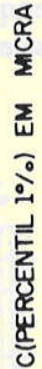

gido que está este perfil por afloramentos rochosos submersos, que dissipam aí a energia das ondas geradas pelos ventos $\mathrm{S}$.

$\mathrm{Na}$ passagem do estágio I para o II começa a haver uma predominância de ventos provindos de $\mathrm{E}$ e NE (Farias et al. 1985). Os ventos de NE, que provocam uma deriva litorânea de sedimentos do perfil 2 para o 1 (Fig. 1), à semelhança do observado no trânsito de inateriais do perfil 1 para o 2, vão transportar principalmente as frações granulométricas mais grossas fazendo diminuir a granulometria no perfil 2 (Figs. 3 e 4). Ao mesmo tempo, porém, os ventos de $\mathbf{E}$, que geram frentes de onda que se aproximam 
subparalelamente à praia (Fig. 1), fazem retornar ao perfil 1 o material fino retirado durante a época de ventos S. Dessa maneira, o fato de a granulometria no perfil 1 também diminuir na passagem do estágio I para o II (Figs. 3 e 4) deve estar relacionado a um maior aporte de material fino da antepraia para a face da praia do que de material grosso do perfil 2 para o 1 . De uma maneira geral, essas características se mantêm essencialmente as mesmas até o limite entre os estágios II e III, quando voltam a prevalecer, como já se apontou, as mesmas condições existentes no início do estágio I. Apenas, entre fins de março e de setembro de 1983, a granulometria, como uma tendência geral, aumenta ligeiramente no perfil 1 (Figs. 3 e 4), tendência esta que não se verifica, todavia, no perfil 2 . A presença de ventos provindos de SE neste período de tempo (Farias et al. 1985) parece estar relacionada com este fato. Assim, esses ventos, embora um pouco mais fracos que os de $\mathrm{S}$, geram ainda ondas destrutivas (Farias et al. 198.5) que, aproximando-se praticamente paralelas à praia (Fig. 1), retiram algum material granulometricamente fino da face da praia para a antepraia, fazendo gradativamente aumentar a granulometria do perfil 1 . Da mesma sorte que os ventos $S$, porém, as ondas geradas pelos ventos de SE dissipam sua energia nos afloramentos rochosos submersos defronte ao perfil 2, não exercendo, portanto, nenhuma influência nesse perfil.

Quanto à relação verificada de uma diminuição do selecionamento com o aumento da granulometria, este fato já tinha sido observado anteriormente por Friedman (1962, 1967), Hails (1967), Sonu (1972) e Chakrabarti (1977), entre outros. Normalmente, como constata Sonu (op. cit.), isto é observado para partículas inferiores a $1 \mathrm{~mm}$, uma relação inversa sendo verdadeira para partículas mais grossas. Essa relação é notável quando se comparam, nos perfis 1 e 2, os gráficos das variações dos valores da mediana e do desvio-padrão (Figs. 3 e 5). Assim, em ambos os perfis, nos estágios I e III, nos quais as medianas têm maiores valores, os selecionamentos são mais baixos, uma relação inversa sendo observada no estágio II.

Em relação à assimetria, observa-se que a mesma não mostra nenhuma relação com os ciclos de erosão e construção, devendo isso ser creditado provavelmente ao fato de ser ela um parâmetro muito sensível e, portanto, estar mais passível de espelhar as pequenas mudanças diárias no perfil da praia, que terminariam por obscurecer as grandes mudanças sazonais. Desse modo, as pequenas quantidades de sedimentos, grossos ou finos - que podem diariamente ser retiradas ou adicionadas ao sedimento praial e não alterariam significativamente os outros parâmetros aqui estudados -, porém fazer variar bastante o valor da assimetria, entendimento este que foi também anteriormente apontado por Duane (1964).

Um outro aspecto em que os atributos texturais analisados neste trabalho, inclusive a assimetria, mostraram-se de grande utilidade na caracterização ambiental está relacionado ao fato deles diferenciarem, do ponto de vista de seus níveis de energia, as praias correspondentes aos perfis 1 e 2. Efetivamente, como já anteriormente mencionado, esses perfis apresentam características fisiográficas distin- tas, consubstanciadas, basicamente, pela presença na antepraia superior defronte ao perfil 2, o que não ocorre no 1 , de afloramentos rochosos que protegem a referida praia, dissipando aí a energia das ondas e impedindo o tráfego de materiais da antepraia para a face da praia, e vice-versa. Assim, por se tratar de um trecho praial sujeito a uma maior ação da turbulência das ondas, o perfil 1 apresenta, de uma maneira geral, maiores valores da mediana, do percentil de $1 \% \mathrm{e}$, conseqüentemente, como se discutiu anteriormente, maiores valores de selecionamento. Da mesma sorte, por aí haver uma maior variação no nível de energia das ondas, há também uma maior variabilidade nos valores dos referidos atributos texturais, conforme já se apontou. Quanto à assimetria, observa-se que as amostras do perfil 2 apresentam, mais consistentemente, valores mais baixos de assimetria que as do perfil 1, o que, segundo também observou Nordstrom (1977) em amostras de outras praias, deve ser creditado à menor variabilidade na energia das ondas no perfil 2 e, conseqüentemente, a um menor número de mudanças em seu perfil de praia, como, aliás, apontam Farias et al. (1985). Ademais, Friedman (1961) menciona que areias praiais médias e finas normalmente são mais assimetricamente negativas que positivas, enquanto as areias grossas tanto podem ser assimetricamente positivas quanto negativas. Este fato pode ser constatado ao se compararem os perfis 1 e 2 . Efetivamente, o perfil 2, constituído em sua grande maioria de areias médias $(0,500-0,25 \mathrm{~mm})$ (Fig. 3 ), apresenta uma maior parte de suas amostras com assimetria negativa que positiva (Fig. 6). Já no perfil 1, de areias grossas (1,000-0,50 mm) (Fig. 3), há um equilíbrio entre o número de amostras com assimetria negativa e positiva (Fig. 6). Por fim, quanto ao diagrama CM, diferentes são os trabalhos que têm mostrado poder o mesmo ser usado como indicador das condições hidráulicas sob as quais um sedimento foi depositado (Passega 1957, 1964, 1977, Passega et al. 1967, Passega \& Byramjee 1969). Os diagramas CM construídos a partir das amostras coletadas nos perfis 1 e 2 (Fig. 7) refletem claramente a alta energia do ambiente praial, bem como permitem diferenciar as características hidráulicas que prevalecem nesses perfis. Ambos os diagramas mostram um padrão de distribuição de pontos típico de praias com alta energia, sendo que o perfil 2, segundo os critérios definidos por Passega (1957), indica, à semelhança do evidenciado pelos outros parâmetros acima analisados, um nível de turbulência das águas proviocada pela ação das ondas bem menor do que no perfil 1, o que pode ser atestado no exame da figura 7, onde se observa que, no perfil 2, a maior parte das amostras apresenta valores de $\mathrm{C}$ inferiores a 1.000 micra, enquanto, no perfil 1, a grande maioria mostra valores superiores àquele. Já um padrão semelhante de maior dispersão de pontos no perfil 1 que no 2 (Fig. 7) é considerado por Passega (1977), em casos semelhantes, como uma evidência, no perfil 1, de variações mais bruscas no nível de turbulência das águas provocada pela ação das ondas.

Agradecimentos Os autores externam seus agradecimentos ao Prof. Umberto Costa pela versão do resumo para o Inglês.

\section{REFERENCIAS BIBLIOGRÁFICAS}

CHAKRABARTI, A. - 1977 - Polymodal composition of beach sands from the east coast of India. J. Sed. Petrol., 47:634-641.
DAVIS, R.A. - 1978 - Beach sedimentology of Mustang and Padre islands: a time-series approach. J. Geol., 86:35-56. 
DINGLER, J.R. - 1981 - Stability of a very coarse-grained beach at Carmel, California. Mar. Geol., 44:241-252.

DIRETORIA DE HIDROGRAFIA E NAVEGAÇÃO-DHN - 1976 - Roteiro da costa leste do Brasil. Marinha do Brasil, 284 p.

DUANE, D.B. - 1964 - Significance of skewness in recent sediments, Western Pamlico Sourad, North Carolina. J. Sed. Petrol., 34:864-874.

EVANS, O.F. - 1939 - Sorting and transportation of material in the swash and backwash. J. Sed. Petrol., 9:28-31.

FARIAS, F.F.; BITTENCOURT, A.C.S.P.; ZANINI Jr., A.; DOMINGUEZ, J.M.L. - 1985 - Variações temporais e espaciais na dinâmica de sedimentação da praia de Armação, Salvador/Ba. Rev. Bras. Geoc., 15(1):48-54.

FOLK, R.L. \& WARD, W.C. - 1957 - Brazos River bar: a study in the significance of grain size parameters. J. Sed. Petrol., 27:3-26.

FRIEDMAN, G.M. - 1961 - Distinction between dune, beach, and river sands from their textural characteristics. J. Sed. Petrol., $31: 514-529$

FRIEDMAN, G.M. - 1962 - On sorting, sorting coefficients, and the log-normality of the grain-size distribution of sandstones. J. Geol., 70:737-753.

FRIEDMAN, G.M. - 1967 - Dynamic processes and statistical parameters compared for size frequency distribution of beach and river sands. J. Sed. Petrol., 37:327-354.

GORSLINE, D.S. - 1966 - Dynamic characteristics of west Florida Gulf coast beaches. Mar. Geol., 4:187-206.

HAILS, J.R. - 1967 - Significance of statistical parameters for distinguishing sedimentary environments in New Wales, Australia. J. Sed. Petrol., 37:1059-1069.

INMAN, D.I. \& FILLOUX, J. - 1959 - Beach cycles related to tide and local wind wave regime. J. Geol., 68: 225-231.

KOMAR, P.D. - 1977 - Selective longshore transport rates of different grainsize fractions within a beach. J. Sed. Petrol., 47: 1444-1453.

KOWSMAN, R. - 1970 - Variações de curto e longo prazo de um perfil da praia de Copacabana - Rio de Janeiro. Inst. Pesq. da Marinha; Ministério da Marinha, Rio de Janeiro. 16 p. (Pub. no 39).
NORDSTROM, K.F. - 1977 - The use of grain-size statistics to distinghish between high-and-moderate-energy beach environments. J. Sed. Petrol., 47:1287-1294.

PASSEGA, R. - 1957 - Texture as characteristic of clastic deposition. AAPG Bull., 41:1952-1984.

PASSEGA, R. - 1964 - Grain size representation by CM patterns as a geological tool. J. Sed. Petrol., 34:830-847.

PASSEGA, R. - 1977 - Significance of CM diagrams of sediments deposited by suspensions. Sed., 24:723-733.

PASSEGA, R.; RIZZINI, A.; BORGHETTI, G. - 1967 - Transport of sediments by waves, Adriatic coastal shelf, Italy. AAPG Bull., 51:1304-1319.

PASSEGA, R. \& BYRAMJEE, R. - 1969 - Grain-size image of clastic deposits. Sed., 13:233-252.

PEIXOTO, S.C. - 1968 - Os fatores condicionantes do problema da cidade de Salvador, Salvador, 208 p. (Tese de Livre-Docência, Fac. Filosofia, UFBa).

SANTOS, R.F.A. dos - 1962 - Chuvas na Bahia. Bahia, DNOCS.

SCHWARTZ, M.L. - 1968 - The scale of shore erosion. J. Geol., $76: 508-517$.

SEPLANTEC - 1978 - Atlas climatológico do Estado da Bahia, documento sintese. Salvador, Centro de Planejamento da Bahia (CEPLAB). $191 \mathrm{p}$.

SHEPARD, F.P. - 1950 - Beach cycles in Southern California. Beach Erosion Board, Corps of Engineers (Tech. Memo. 20).

SHEPARD, F.P. \& LA FOND, E.C. - 1940 - Sand movement along the Scripps Institution pier, California. Am. J. Sci., 238:272-285.

SONU, C.J. - 1972 - Bimodal composition and cyclic characteristics of beach sediment in continuously changing profiles. J. Sed. Petrol., 42:852-857.

ZIEGLER, J.M.; HAYES, C.R.; TUTTLE, S.D. - 1959 - Beach changes during storms on outer Cape Cod, Massachusetts. J. Geol., 67:318-336.

ZIEGLER, J.M. \& TUTTLE, S.D. - 1961 - Beach changes based on daily measurements of four Cape Cod beaches. J. Geol., 69:583-599.

MANUSCRITO 413

Recebido em 22 de dezembro de 1986 Revisão aceita em 5 de agosto de 1987

Faz-se Ciência com fatos, como uma casa com pedras; porém, uma acumulação de fatos não é Ciência, exatamente como um monte de pedras não é uma casa. 